\title{
OS PRINCÍPIOS CONSTITUCIONAIS DA ATIVIDADE ECONÔMICA
}

\author{
Egon Bockmann Moreira*
}

RESUMO: O texto é a transcrição ipsis litteris da prova escrita realizada pelo autor em junho de 2006, no Concurso Público para Professor Assistente da Faculdade de Direito da Universidade Federal do Paraná. O tema sorteado para a prova foi o ponto relativo aos princípios constitucionais da ordem econômica - o que exigiu o estabelecimento de algumas premissas cognitivas (o conceito de princípios, a formação e a consolidação da Constituição Econômica e as linhas gerais da Constituição Econômica brasileira de 1988). O texto segue analisando os princípios constitucionais expressos e implícitos do artigo 170 (e incisos) da Constituição de 1988, com especial enfoque para os princípios da dignidade da pessoa humana, justiça social e livre iniciativa.

\section{PREMISSAS COGNITIVAS}

\section{$1.1 O$ conceito de princípios}

O conceito de princípios experimentou significativas variações na dogmática jurídica, sobretudo a partir de meados do século XX. A sua inserção e compreensão ampliativa no corpo das Constituições implicou a consolidação do conceito de princípios como normas jurídicas, a instruir a hermenêutica de todo o Ordenamento. Mas essa consolidação exige um "clareamento"

* Mestre e Doutor em Direito pelo PPGD da UFPR. Professor Adjunto da Faculdade de Direito da UFPR. Coordenador do Núcleo de Pesquisa em Direito Econômico do PPGD da UFPR. doutrinário - compreendendo as fases evolutivas do conceito.

Isso porque até o início do século $\mathrm{XX}$ os princípios eram tidos ou como critérios hermenêuticos ou como meros instrumentos de colmatação das lacunas normativas (heterointegração, na dicção de EMILIO BETTI). ${ }^{1}$ Isso correspondia à pretensão de um "sistema fechado de normas", típico das doutrinas de um normativismo puro, ou a "máximas da cultura histórica", típicas de um jusnaturalismo.

\footnotetext{
${ }^{1}$ Vide o art. $4^{\circ}$ da LICC e o art. 12 do CPC, que reservam aos "princípios gerais de direito" a função de preenchimento de lacunas, depois da analogia e dos costumes.
} 
O primeiro a tratar os princípios como normas foi Boulanger, em artigo publicado no ano de 1950 (JOSEPH ESSER; PAULO BONAVIDES; TERCIO SAMPAIO FERRAZ JR. corroboram a tese). Os princípios eram vistos como normas especiais em razão de sua abstração: eram aplicáveis a um número ilimitado de casos (ao contrário das regras, que só seriam aplicadas aos casos-limite previstos em suas hipóteses de incidência).

A segunda fase da compreensão dos princípios como normas jurídicas é representada por Joseph Esser e Karl Larenz. Para aquele, os princípios seriam as normas fundantes, os "starting points" da atividade hermenêutica. Serviriam de estrutura à compreensão, interpretação e aplicação das normas. Já para Larenz, os princípios teriam também uma dissociação material quando em comparação com as regras, uma vez que não disporiam da mesma tradicional estrutura "hipótese de incidência $\rightarrow$ conseqüência normativa”. Teriam eles, os princípios, uma estrutura mais aberta - o que possibilitaria a sua compreensão como normas fundamentais do sistema.

Essa escola tem grandes adeptos no Brasil, sendo importante a menção a Celso Antônio Bandeira de Mello ("mandamentos nucleares do sistema").

A terceira fase dos princípios como normas está em Dworkin e Alexy. Estes estabelecem uma distinção forte entre princípios e regras, que tem por base uma diferença essencial entre suas estruturas lógico-normativas. Para Dworkin, as regras se aplicam segundo o critério do "all or nothing at all": tudo ou nada; enquanto os princípios têm uma estrutura que permite convivência harmoniosa em casos de eventuais colisões. Para eles, princípios, o critério de solução das pseudo-antinomias residiria na "questão de peso ou importância", num método de ponderação que compreende: $a$ ) a análise das normas postas em jogo; $b$ ) a análise do caso concreto (também um "prius metodológico", na expressão de Castanheira Neves) e $c$ ) na correlação concreta entre $a$ ) e $b$ ).

Porém, Alexy foi avante e conferiu maior precisão teleológica ao conceito elaborado por Dworkin. Para o jurista alemão, princípios são normas que estabelecem deveres de otimização-são "mandamentos de otimização" que instalam um dever de máxima efetividade e máxima aplicabilidade possível.

Considerações à parte a recente evolução do debate - sobretudo com a obra de Humberto Ávila, que questiona as classificações de Dworkin e de Alexy (como também o faz em relação a tradicionais "princípios" do Direito Público brasileiro²) fato é que cabe ao estudioso fazer uma clarificação prévia quando do enfrentamento do tema ao nível constitucional. Isso porque não é consistente a tomada de uma posição que procure conciliar critérios classificatórios diferentes (p. ex., o critério material de Larenz com o critério lógico-estrutural de Dworkin). A constatação de que, para Alexy, o princípio "nullum crimen, nulla poena, sine lege" é uma regra prova demais.

Não que se ouse imputar acertos ou erros a alguma das teorias. O que se põe é - na dicção de Carrió - um contraste da utilidade prática de seus enunciados. ${ }^{3}$

${ }^{2}$ Humberto Ávila considera que o "princípio da supremacia do interesse público" não é um princípio jurídico. Mais do que isso, sustenta que norma não é.

${ }^{3}$ Em seu "Notas sobre Direito e Linguagem", Genaro Carrió compara as classificações jurídicas aos critérios de medição anglo-saxão (polegadas) e o quase-universal sistema métrico-decimal. Ambos são perfeitos e válidos. 
Assim, e em vista a profusão do uso do termo "princípios" em nossa Constituição de 1988, talvez seja mais adequada uma compreensão à lá Larenz, Celso Antônio e Geraldo Ataliba. ${ }^{4}$ Essa é a primeira premissa cognitiva para o exame dos princípios constitucionais na Ordem Econômica brasileira.

\subsection{O conceito de Constituição Econômica}

O Direito Econômico, a regulação pública da economia, é um dado recente na História da Humanidade. O seu nascimento se deu no período da Primeira Grande Guerra (1914/1918), que pôs fim ao "longo século XIX".

Até então, vigia uma concepção liberal do relacionamento do Estado com a economia, oriunda sobretudo das Revoluções burguesas do século XVIII (Revolução Americana, 1776; Revolução Francesa, 1789). A lógica que orientava as relações do Estado com a economia era de uma racionalidade substitutiva: ou um ou outro, assegurando-se o domínio econômico como território exclusivo das pessoas privadas. ${ }^{6}$

Não foi devido a um acaso que a Declaração dos Direitos do Homem e do Cidadão (1789) consagrava a propriedade

\footnotetext{
${ }^{4}$ Isto é, os princípios como normas fundamentais ou "mandamentos nucleares do sistema". São normas de estrutura e não propriamente normas de conduta (apesar de imporem juridicamente as condutas, sem a estrutura normativa clássica).

${ }^{5}$ A expressão é de Fábio Konder Comparato, que a usa tanto no "Afirmação Histórica dos Direitos Humanos" como no artigo "O indispensável Direito Econômico".

${ }^{6}$ Daí doutrinadores do porte da ilustre professora Lúcia Valle Figueiredo descreverem que seria uma repetição viciosa a expressão "domínio econômico privado" - afinal, o domínio econômico é só dos privados. O Estado nele intervém!
}

como um direito "sagrado e inviolável" e instituía o dever de os tributos serem instituídos por meio de lei.

Considerações à parte eventuais percalços (a criação da ICC, nos EUA, em 1887, é um exemplo ${ }^{7}$ ), fato é que o domínio econômico era um território hostil aos Estados.

Com a Primeira Grande Guerra e o PósGuerra, os Estados viram-se constrangidos a intervir na economia (tanto sob a forma regulatória, com a edição de normas cogentes a disciplinar a conduta dos privados, como sob a forma de gestão, com a instalação de fábricas e atividades industriais controladas pelos entes públicos).

A primeira Constituição a tratar de temas econômicos foi a mexicana, de 1917. Mas foi a Constituição alemã de 1919, a "Constituição de Weimar", a ter um capítulo exclusivo que regia a vida econômica de uma nação. É clássica a expressão "a propriedade obriga", que constava do art. 153 da Constituição de Weimar.

Então, o Estado passou a incorporar a economia em suas diretrizes primeiras e a intervir com cada vez mais intensidade no domínio econômico. Afinal de contas, e como escreveu Comparato, consagrar o "laissezfaire" implicaria celebrar um "laissez ne pas faire" - vez que a economia privada já não mais dispunha de forças.

O grande teórico da economia dessa fase foi Keynes - cujas obras tanto influenciaram as formas de intervenção do Estado na

${ }^{7}$ Trata-se da Interstate Commerce Commission, criada com nítido desiderato antitruste, visando a reprimir o abuso do poder econômico no setor de ferrovias estadunidense. É a primeira agência reguladora Norte-Americana. 
economiaa ponto de, em 1966, Milton Friedman proclamar: "agora somos todos keynesianos". ${ }^{8}$

Pois é a partir de então - início do século $\mathrm{XX}$ - que a economia se torna uma questão de Estado, senão a mais importante delas. E é nessa fase histórica que os textos constitucionais vêm a incorporar os "direitos de segunda geração", que exigem do Estado uma postura pró-ativa em relação a determinadas necessidades socioeconômicas dos cidadãos. A partir de meados do século XX (o Brasil foi uma das primeiras nações a beber na fonte de Weimar, com a Constituição de 1934), todas as nações ocidentais haviam incorporado essa compreensão da magnitude axiológico-normativa do relacionamento do Estado com a economia (privada que se tornava pública). ${ }^{9}$

Isso significa a necessidade de uma compreensão contextualizada e diferenciada dos princípios constitucionais da Ordem Econômica. Não é válida a leitura da Constituição de 1988 - que celebra um sistema econômico capitalista - à luz de parâmetros abstratos elaborados num momento anterior da celebração positiva de uma ordem econômica constitucional. ${ }^{10}$

\footnotetext{
${ }^{8}$ Keynes foi tido pelos Estados capitalistas como o grande salvador em relação às economias comunistas. Porém, na década de 1980 teve as suas teorias refutadassobretudo pela dogmática neoliberal - e juntou-se a Marx, como um deus que fracassara.

${ }^{9}$ A evolução desse relacionamento foi de tal forma que autores como Washington Albino de Sousa, Eros Grau e Fábio Nusdeo questionam o uso do termo “intervenção". Num Estado de iniciativa econômica dual, seria mais adequado falar-se de "atuação econômica do Estado", não se "intervenção".

${ }^{10}$ Daí por que não se pode compreender a economia brasileira sob o enfoque de um liberalismo econômico europeu e estadunidense dos séculos XVIII e XIX.
}

A compreensão do "porquê" histórico facilita a leitura e a integração do "para quê" da Ordem Econômica constitucional.

\section{LINHAS GERAIS DA CONSTITUIÇÃO ECONÔMICA DE 1988}

Como já mencionado, a Constituição de 1988 celebra um sistema econômico capitalista, em que os fatores de produção são detidos pelos agentes privados, que deles dispõem e podem deles valer-se para a obtenção de lucro. Não será a circunstância de o Estado poder intervir (seja mediante atos de gestão seja mediante atos normativos) que desnatura a essência da Constituição Econômica brasileira de 1988. A leitura dos arts. $1^{\circ}$ e 170 torna a constatação clara.

Porém, isso não significa que a leitura do modelo de economia capitalista celebrado pela Carta de 1988 implique uma compreensão de um capitalismo liberal "puro", conformado segundo uma escola liberal clássica (ADAM SMITH, DAVID RICARDO) ou neoclássica (ALFRED MARSHALL) - e muito menos neoliberal (HAYEK, FRIEDMAN, STIGLER).

A essência da Constituição de 1988 é a de um Estado Democrático Social de Direito celebrador de deveres de implementação e compreensão de uma Constituição Econômica voltada à celebração da dignidade da pessoa humana; da justiça social e do pleno emprego.

Por outro lado, perspectivas descontextualizadas no tempo (século $\mathrm{XIX}$ versus séculos $\mathrm{XX}$ e XXI) e no espaço (EUA ou Europa ocidental versus Brasil) não possibilitam ao intérprete a leitura de uma "Constituição viva". O dinamismo e as necessidades econômico-socioculturais próprias do Estado brasileiro contemporâneo 
exigem uma hermenêutica que não se submeta ao método tradicional do "silogismo interpretativo", mas que alie a unidade da Constituição à metodologia ponderativa (que não despreza os fatos ${ }^{11}$ ) - tudo isso na busca da concretização da própria "raison d'être" do Texto Maior: a busca perene e a consolidação persistente de um Estado Democrático Social de Direito.

Postas essas linhas gerais da ordem Econômica da Constituição de 1988, podemos passar ao exame de dez dos seus princípios.

\section{OS PRINCÍPIOS DA ORDEM ECONÔMICA DE 1988}

A leitura dos princípios constitucionais da Ordem Econômica tem duas diretrizes básicas: o princípio da unidade ("A Constituição não pode ser lida em tiras" EROS ROBERTO GRAU) e o princípio ponderativo-compatibilizador (a fim de obter a máxima efetividade dos princípios).

Daí a eleição do primeiro deles: o princípio da dignidade da pessoa humana.

\subsection{O princípio da dignidade da pessoa humana}

Não obstante ser objeto recente de preocupações da doutrina brasileira, fato é que a dignidade da pessoa humana assumiu com firmeza a condição de eixo central do sistema, de diretriz maior a irradiar-se na cognição e interpretação das demais normas. Por todos, a doutrina de Rizzatto Nunes, de Sarmento, de Justen Filho, de Sarlet e de David Araújo.

\footnotetext{
${ }^{11}$ Mas não os têm como premissas interpretativas, como pontifica o método tópico.
}

O princípio da dignidade da pessoa humana é o "epicentro axiológico" do Direito brasileiro (DANIEL SARMENTO), tanto ao nível constitucional como infra.

Daí por que a ordem econômica constitucional brasileira deva ser compreendida à luz desse princípio (Constituição, art. $1^{\circ}$ e 170).

A dignidade da pessoa humana é um fim em si mesmo, de caráter íntegro e irrenunciável. O Estado tem, em relação a ela, deveres negativos (abster-se de qualquer ação ou omissão que porventura a agrida) e deveres positivos (assumir condutas que prestigiem de forma ativa a dignidade do Homem).

Essa é a diretriz primeira da compreensão de toda a Constituição; essa é a diretriz primeira de todos os princípios da Ordem Econômica.

\subsection{O fundamento da Ordem Econômica: a valorização do trabalho}

O caput do art. 170 da constituição estabelece como fundamento econômico a valorização do trabalho. Esse fundamento, portanto, pode ser lido como um princípio; uma norma que configura a estrutura do sistema constitucional brasileiro. ${ }^{12}$

A valorização do trabalho quer significar que todos os indivíduos têm direito ao trabalho. Mas não a qualquer trabalho, porém apenas aqueles que sejam dignos e adequados, segundo uma perspectiva que atenda à concepção pessoal de adequação física, psicológica e moral.

${ }^{12}$ Note-se que a Constituição prevê a valorização do trabalho e a livre iniciativa. Esta não é submetida à mesma dimensão axiológico-normativa que aquela. Ambos os fundamentos merecem uma compreensão diferenciada, portanto. 
São proibidos, portanto, os trabalhos que impliquem degradação do ser humano (p. ex., "freak shows") e, mais do que isso, é crime o trabalho escravo.

O direito ao trabalho, compreendido na perspectiva constitucional da valorização do trabalho humano, importa o dever ativo do Estado de promover intervenções (diretas ou indiretas; ativas ou fomentadoras) que façam cumprir esse princípio constitucional.

\subsection{O fundamento da Ordem Econômica: a livre iniciativa}

Estampado no art. $1^{\circ}$ e no art. 170 da Constituição, o princípio da livre iniciativa deve ser lido à luz da compreensão contextual acima exposta.

Isto é, não é possível a celebração de um princípio da livre iniciativa à luz da sua fonte primária que são as Revoluções burguesas do século XVIII. ${ }^{13}$

A livre iniciativa da Carta de 1988 faculta ao empreendedor a possibilidade de instalar e realizar os seus investimentos, de competir lealmente nos mercados e de auferir lucros (desde que não abusivamente).

Assim, a livre iniciativa possui os seguintes desdobramentos: $1^{\circ}$ ) liberdade de instalação e alocação de investimentos; $2^{\circ}$ ) liberdade de competição e $3^{\circ}$ ) liberdade de gestão.

Os empresários são livres para tomar as suas decisões de forma autônoma, realizar os investimentos pertinentes e auferir os lucros. Porém, como no caso das demais liberdades, a liberdade de iniciativa não é absoluta. Experimenta, quando menos,

${ }^{13}$ O termo "fonte" aqui compreendido não no sentido jurídico, mas histórico do mesmo. os seguintes lindes: $1^{\circ}$ ) limites jurídicos: há setores exclusivos do Estado, como os serviços públicos e os monopólios de petróleo e minerais nucleares; $2^{\circ}$ ) limites econômicos: os chamados "monopólios naturais", em que a presença de mais de um agente econômico ou encontra óbices tecnológicos (frequiência das ondas de telefonia celular, p. ex.) ou físicos ( v.g. aeroportos, ferrovias, portos); $3^{\circ}$ ) limites socioculturais: correlacionados aos princípios da dignidade da pessoa humana e da valorização do trabalho (proibição à exploração da prostituição alheia ou de exibições de humilhação de seres humanos com peculiaridades físicas extravagantes, p. ex.).

A liberdade de iniciativa traz consigo a liberdade de profissão - desdobrando aquela num plano individual. As pessoas têm a liberdade de optar pela profissão que mais as agrade, desde que respeitados os limites (acadêmicos, legais e regulamentares a elas pertinentes).

\subsection{O princípio da propriedade a sua função social}

A Constituição de 1988, capitalista que é, celebra a propriedade. $\mathrm{O}$ direito de propriedade teve a sua compreensão variante na História da Humanidade: desde a concepção de um direito sagrado e absoluto (Declaração dos Direitos do Homem e do Cidadão, 1789) até a compreensão de um bem de apropriação e gestão coletivas (socialismo), passando pelos conhecidos direitos de usar, fruir, dispor e abusar.

A sua positivação na Constituição de 1988, ao lado da sua "função social" resulta numa compreensão específica: a propriedade funcionalizada, destinada não só a atender 
os interesses imediatos do proprietário, mas sim direcionada ao atendimento de interesses sociais.

O conceito remete à idéia de "função" em Direito Administrativo: exerce função aquele que gere bem alheio no interesse de terceiro recebendo essa incumbência mediante um plexo de deveres para cuja execução dispõe de um conjunto de poderes preestabelecidos (tal como o tutor ou o curador). ${ }^{14}$

Claro que a propriedade privada e a sua função social não podem ser compreendidas segundo o conceito de Direito Administrativo em sentido estrito: isso implicaria uma "socialização" do direito de propriedade concepção antitética ao modelo capitalista celebrado na Constituição.

Mas o conceito permite a compreensão de que há um "plus" jurídico a direcionar o direito de propriedade ao atendimento de interesses sociais, muitas vezes exógenos (e por que não antitéticos?) ao do proprietário.

Isso sobretudo quando se lê a função social da positivada no Capítulo da ordem Econômica: a propriedade econômica, os bens e fatores de produção, devem atender a um desiderato que não - unicamente - aquele exclusivo do proprietário.

\subsection{O princípio da soberania}

Luiz Alberto David de Araújo, citando Dalmo Dallari, lembra que a soberania é um conceito relativo à independência políticoinstitucional de um país. O princípio da soberania significa, na leitura integrada do

${ }^{14}$ Aliás, Fábio Konder Comparato de há muito afirmou que a Democracia é um governo de funções, não de dominações. art. 170 com o art. $4^{\circ}$ da Constituição, que as decisões econômicas (públicas ou privadas) devem ser autônomas e independentes de gestões internacionais. Como nação soberana que é, o Brasil deve direcionar as suas decisões político-econômicas de forma a não se subordinar a interesses internacionais.

O princípio da soberania tem repercussão prática não só no que diz respeito à política econômica interna e externa, mas igualmente quanto a organismos econômicos internacionais que porventura lancem decisões impositivas: estas só serão vinculantes caso oriundas de Tratados Internacionais legítima e devidamente incorporados à Ordem Jurídica interna.

\subsection{O princípio da livre concorrência}

Desdobramento da livre iniciativa, o princípio da livre concorrência implica a ausência de óbices a que os agentes econômicos ingressem nos mercados e se relacionem de forma horizontal com os demais operadores.

A livre concorrência proíbe privilégios derivados do uso abusivo do poder econômico, bem como aquelas vantagens porventura oriundas de intervenções públicas na economia.

A livre concorrência prestigia a liberdade de ingresso (vedando as barreiras de entrada e de saída); a liberdade de exercício e de gestão (celebrando o uso do poder econômico de cada agente de uma forma leal e proibindo o abuso do poder econômico). São proibidas violações à livre concorrência sob a forma da conduta dos agentes (v.g., o "dumping") ou sob a forma das estruturas empresariais.

A livre concorrência pode ser concebida como uma concorrência-fim (Escola de Harvard) ou como uma concorrência-meio. 
No primeiro caso, a finalidade da defesa da concorrência é um valor absoluto - tanto que se proíbe a conduta que possa causar danos potenciais à concorrência. Já a segunda escola vê na concorrência um meio, um instrumento de busca de eficiência alocativa de recursos sociais - o que permite o prestígio a condutas monopolistas, p. ex., desde que a eficiência alocativa advenha como resultado delas.

Por fim, uma última ressalva quanto à livre concorrência: não existe notícia histórica de um país que porventura o modelo perfeito de livre concorrência tenha operado. Trata-se de um modelo teórico, concebido com um número certo de variáveis endógenas, as quais permitem o resultado ideal quanto à distribuição de recursos na sociedade.

\subsection{O princípio da defesa do consumidor}

A defesa do consumidor vem positivada na Constituição da República de 1988 tanto na condição de Direito Fundamental (art. $5^{\circ}$ ) como na condição de princípio da Ordem Econômica.

Isso significa que a defesa do consumidor há de ser interpretada e aplicada como diretriz incrementadora do princípio da dignidade da pessoa humana. O ser humano há de ser considerado em sua integralidade e com valoração sobranceira nas relações econômicas.

Aliás, ao declarar o princípio da "defesa" do consumidor, a Constituição torna indeclinável a premissa cognitiva quanto à hipossuficiência da pessoa-consumidor.

Em suas relações econômicas (tanto com os Estado como com as demais pessoas privadas), o consumidor tem o direito público-subjetivo de ser tratado condignamente, com respeito, e sempre em relações nas quais não haja abusos por parte do detentor do poder econômico.

Ao seu tempo, o Estado é titular do dever de promover a defesa ativa do consumidor. O Código de Defesa do Consumidor e os PROCONs são dois exemplos do cumprimento desses deveres por parte dos Poderes Públicos.

\subsection{Princípio da defesa do meio ambiente}

A positivação do meio ambiente no Capítulo da Ordem Econômica (além de sua previsão no art. 225 da Constituição) relaciona-se precipuamente com o princípio do desenvolvimento sustentável.

Oprincípiododesenvolvimentosustentável é uma das chaves para a compreensão do Direito Ambiental contemporâneo. Significa que as atividades a serem desenvolvidas pelos agentes econômicos não podem implicar danos ambientais (sobretudo os irreparáveis) nem para o presente, nem para o futuro. ${ }^{15}$

A inserção do meio ambiente na ordem Econômica celebra um "antropocentrismo ecológico": uma compreensão não apenas antropocêntrica nem tampouco eco-fundamentalista. Trata-se de uma ponderação entre o direito à livre iniciativa e o dever (público e privado) de bem cuidar, preservar e manter o meio ambiente ecologicamente equilibrado.

${ }^{15}$ Isso por dois motivos básicos: a) há danos ambientais que são definitivos (a extinção de uma espécie, p. ex.) e b) o custo de reparar o dano é superior ao de preveni-lo. 


\subsection{Princípio da redução das desigualdades e busca do pleno emprego}

Este princípio pode ser lido sob três ópticas complementares.

Por um lado, integra-se aos arts. $1^{\circ}$ e $3^{\circ}$ da Constituição Dirigente brasileira, impondo deveres ativos ao Estado na condução dos negócios públicos. Estado Democrático Social de Direito que é, o Estado brasileiro deve cumprimento aos preceitos impositivos de implementação de deveres públicos relativos ao bem-estar coletivo.

Por outro lado, num ângulo subjetivo complementar, está a atribuição de direitos subjetivos públicos aos cidadãos, que podem (devem) ter prestigiada a sua capacidade de deduzir pleitos que prestigiem esse princípio da Ordem Econômica constitucional.

Por fim, à União cumpre o dever de atenuar as desigualdades regionais, promovendo a distribuição de rendas e recursos de forma proporcional à demanda dos Estado. Isso envolve também a instalação e o planejamento de Planos de Desenvolvimento Regionais.

\subsection{O princípio de proteção às pequenas empresas nacionais}

Este princípio estabelece o dever normativo ativo de o Estado brasileiro promover o fomento e o incentivo de pequenas empresas nacionais.

A política de fomento é uma modalidade de ação econômica que se instalou no segundo Pós-Guerra e teve desenvolvimento acentuado sobretudo na década de 1970. sob a perspectiva jurídica, é um instrumento típico do Estado-Providência. O principal estudo jurídico a respeito do fomento sob a perspectiva normativa pode ser atribuído a Bobbio que - opondo-se às teses de Hayek cunhou o conceito de "sanções positivas" (os estudos estão reunidos na coletânea "Dalla Struttura alla Funzione", de meados da década de 1970).

No Brasil são exemplos do cumprimento desse princípio as leis conhecidas como "Estatuto Jurídico da Micro-Empresa" e "Regime tributário das Micro e Pequenas Empresas". Também a Lei 8.666 (Lei das Licitações e Contratos Administrativos) possui dispositivos que dão cumprimento a esse princípio constitucional expresso. 
